\title{
In Vitro Activities of Eravacycline and Other Antimicrobial Agents against Human Mycoplasmas and Ureaplasmas
}

\author{
(D) Ken B. Waites, ${ }^{\text {a Donna M. Crabb, }}$ a Li Xiao, ${ }^{\text {b Lynn B. Duffy, }}$ a Sixto M. Leal, Jr. ${ }^{a}$ \\ aDepartment of Pathology, University of Alabama at Birmingham, Birmingham, Alabama, USA \\ bDepartment of Medicine, University of Alabama at Birmingham, Birmingham, Alabama, USA
}

\begin{abstract}
We performed in vitro susceptibility testing for eravacycline in comparison to 4 other antimicrobials against 10 Mycoplasma genitalium, 40 Mycoplasma hominis, 44 Mycoplasma pneumoniae, 20 Ureaplasma parvum, and 20 Ureaplasma urealyticum isolates. All eravacycline MICs were $\leq 0.25 \mu \mathrm{g} / \mathrm{ml}$, except that for one isolate of $M$. genitalium, for which the MIC was $2 \mu \mathrm{g} / \mathrm{ml}$. Eravacycline was markedly more potent than tetracycline, azithromycin, moxifloxacin, and clindamycin against all isolates tested, which included 37 macrolide, tetracycline, and/or fluoroquinoloneresistant organisms.
\end{abstract}

KEYWORDS eravacycline, mycoplasma, pneumonia, ureaplasma, urogenital infection ravacycline (TP-434) is a synthetic halogenated tetracycline derivative that is undergoing clinical development by Everest Medicines and has activity against a broad spectrum of microorganisms, including methicillin-resistant Staphylococcus aureus, vancomycin-resistant Enterococcus species, and carbapenem-resistant Gramnegative bacilli (1). Although the eravacycline binding site is similar to that of tetracycline, a significant advantage is that it retains activity against organisms with the two main tetracycline resistance mechanisms, efflux and ribosomal protection (1).

Mycoplasma pneumoniae is a cause of tracheobronchitis and community-acquired bacterial pneumonia (CABP) in children and adults (2). Mycoplasma hominis and Ureaplasma spp. cause a variety of urogenital conditions in adults and are also systemic pathogens in infants (3). Mycoplasma genitalium is an important cause of male urethritis, female cervicitis, and pelvic inflammatory disease, and it may also be associated with adverse pregnancy outcomes $(4,5)$. Invasive disease may occur in persons who are immunosuppressed, particularly in the setting of defects in humoral immunity or organ transplantation $(2,3)$. Treatment of $M$. pneumoniae infections has been complicated by macrolide resistance mediated by mutations in $23 \mathrm{~S}$ rRNA that has spread worldwide over the past 2 decades $(2,6)$. Tetracycline resistance often occurs in $M$. hominis and Ureaplasma species due to ribosomal protection mediated by the tet $M$ transposon (7). Resistance to macrolides due to mutations in 235 rRNA and resistance to to fluoroquinolones due to mutations in parC and/or parE have been documented in these organisms, as well as in M. genitalium $(7,8)$. Tetracyclines have historically not worked well for treatment of $M$. genitalium infections, but high-level resistance has not previously been documented in this species, and no isolates described thus far have been shown to contain tetM (9). Persons who are immunosuppressed and those who have received numerous courses of antimicrobials are at greater risk for having systemic infections with drug-resistant organisms (7). For these reasons, new agents that are not affected by cross-resistance to other drug classes are needed for treatment of Mycoplasma and Ureaplasma infections. There are no published data concerning the in vitro activity of eravacycline against Mycoplasma or Ureaplasma species.

We performed an in vitro study testing eravacycline against a collection of Myco-
Citation Waites KB, Crabb DM, Xiao L, Duffy LB, Leal SM, Jr. 2020. In vitro activities of eravacycline and other antimicrobial agents against human mycoplasmas and ureaplasmas. Antimicrob Agents Chemother 64:e00698-20. https://doi.org/10.1128/AAC.00698-20. Copyright $\odot 2020$ American Society for Microbiology. All Rights Reserved. Address correspondence to Ken B. Waites, kwaites @uabmc.edu.

Received 11 April 2020

Returned for modification 25 May 2020

Accepted 31 May 2020

Accepted manuscript posted online 8 June 2020

Published 22 July 2020 
TABLE 1 MIC summary

\begin{tabular}{|c|c|c|c|}
\hline Organism or drug & MIC range $(\mu \mathrm{g} / \mathrm{ml})$ & $\mathrm{MIC}_{50}(\mu \mathrm{g} / \mathrm{ml})$ & $\mathrm{MIC}_{90}(\mu \mathrm{g} / \mathrm{ml})$ \\
\hline \multicolumn{4}{|c|}{ Mycoplasma genitalium $(n=10)$} \\
\hline Eravacycline & 0.002 to 2 & 0.008 & 0.125 \\
\hline Tetracycline & 0.125 to 32 & 0.25 & 4 \\
\hline Azithromycin & $\leq 0.001$ to 32 & $\leq 0.001$ & 4 \\
\hline Moxifloxacin & 0.032 to 8 & 0.063 & 2 \\
\hline \multicolumn{4}{|c|}{ Mycoplasma hominis $(n=40)$} \\
\hline Eravacycline & 0.002 to 0.008 & 0.004 & 0.008 \\
\hline Tetracycline & 0.016 to 32 & 0.25 & 16 \\
\hline Clindamycin & 0.008 to $>32$ & 0.063 & 0.063 \\
\hline Moxifloxacin & 0.032 to 8 & 0.063 & 0.125 \\
\hline \multicolumn{4}{|c|}{ Mycoplasma pneumoniae $(n=44)$} \\
\hline Eravacycline & 0.004 to 0.008 & 0.008 & 0.008 \\
\hline Tetracycline & 0.25 to 0.5 & 0.5 & 0.5 \\
\hline Azithromycin & $\leq 0.0005$ to $>32$ & $\leq 0.0005$ & 32 \\
\hline Moxifloxacin & 0.125 & 0.125 & 0.125 \\
\hline \multicolumn{4}{|c|}{ Ureaplasma species $(n=40)$} \\
\hline Eravacycline & 0.032 to 0.25 & 0.125 & 0.25 \\
\hline Tetracycline & 0.125 to $>32$ & 0.5 & 8 \\
\hline Azithromycin & 0.5 to $>32$ & 2 & 8 \\
\hline Moxifloxacin & 0.125 to 8 & 0.5 & 2 \\
\hline
\end{tabular}

plasma and Ureaplasma spp. obtained from across the United States, Europe, and China. Organisms included 44 clinical isolates of $M$. pneumoniae (obtained since 2008), 40 isolates of $M$. hominis (30 obtained since 2015), 20 isolates of Ureaplasma parvum, 20 isolates of Ureaplasma urealyticum (37 obtained since 2013), 10 M. genitalium isolates with 2 of them obtained since 2018, and 8 older clinical isolates and reference strains. Organisms included 37 isolates resistant to tetracyclines, macrolides, or fluoroquinolones, alone or in combination. With the exception of 2 recent $M$. genitalium isolates from the same patient, all other isolates were from nonduplicate patients. A complete listing and description of all bacterial isolates tested along with the individual MICs for each of them is provided as Table S1 in the supplemental material. Comparator agents were tetracycline, azithromycin, and moxifloxacin. Clindamycin was substituted for azithromycin for M. hominis due to intrinsic resistance to 14- and 15-membered macrolides (10). Antimicrobial agents were obtained in powdered forms of known purity and dissolved in accordance with their manufacturer's instructions. Inoculum was prepared, then MICs were determined and interpreted using the broth microdilution technique in accordance with Clinical and Laboratory Standards Institute (CLSI) guideline M43-A (11). Organisms were stored frozen at $-80^{\circ} \mathrm{C}$ until thawing for testing. Table 1 summarizes MIC data.

Eravacycline was the most active drug overall against each species. All eravacycline MICs were $\leq 0.25 \mu \mathrm{g} / \mathrm{ml}$, with the exception of that of one $M$. genitalium isolate, which was $2 \mu \mathrm{g} / \mathrm{ml}$. The eravacycline $\mathrm{MIC}_{90}(0.125 \mu \mathrm{g} / \mathrm{ml})$ for $M$. genitalium was 16 -fold lower than that for moxifloxacin $(2 \mu \mathrm{g} / \mathrm{ml})$ and 32-fold lower than those of tetracycline and azithromycin $(4 \mu \mathrm{g} / \mathrm{ml})$. Older strains of $M$. genitalium had much lower MICs for eravacycline $\left(\mathrm{MIC}_{50}=0.008 \mu \mathrm{g} / \mathrm{ml}\right)$ and tetracycline $\left(\mathrm{MIC}_{50}=0.25 \mu \mathrm{g} / \mathrm{ml}\right)$.

All eravacycline MICs tested against $M$. hominis were $\leq 0.008 \mu \mathrm{g} / \mathrm{ml}$. The $\mathrm{MIC}_{90}$ $(0.008 \mu \mathrm{g} / \mathrm{ml})$ was 8 -fold lower than that for clindamycin $(0.063 \mu \mathrm{g} / \mathrm{ml})$ and 16 -lower than that for moxifloxacin $(0.125 \mu \mathrm{g} / \mathrm{ml})$. This collection included one $M$. hominis isolate resistant to clindamycin ( $\mathrm{MIC},>32 \mu \mathrm{g} / \mathrm{ml}$ ), as well as 8 isolates resistant to tetracycline (MICs, 8 to $32 \mu \mathrm{g} / \mathrm{ml}$ ), and 3 isolates resistant to moxifloxacin (MICs, 1 to $8 \mu \mathrm{g} / \mathrm{ml}$ ). Two isolates were resistant to both of these drugs. Eravacycline MICs were unaffected by resistance to clindamycin, tetracycline, and moxifloxacin.

Eravacycline was active against $M$. pneumoniae with all MICs being $\leq 0.008 \mu \mathrm{g} / \mathrm{ml}$. The $\mathrm{MIC}_{90}(0.008 \mu \mathrm{g} / \mathrm{ml})$ was 16 -fold lower than that for moxifloxacin $(0.125 \mu \mathrm{g} / \mathrm{ml})$ and 
64-fold lower than that for tetracycline $(0.5 \mu \mathrm{g} / \mathrm{ml})$. Azithromycin was the most potent agent against 30 macrolide-susceptible isolates (MICs, $\leq 0.0005 \mu \mathrm{g} / \mathrm{ml}$ ), whereas the MICs for 14 macrolide-resistant isolates were 8 to $32 \mu \mathrm{g} / \mathrm{ml}$.

Eravacycline MICs against Ureaplasma species were all $\leq 0.25 \mu \mathrm{g} / \mathrm{ml}$. The $\mathrm{MIC}_{90}$ $(0.25 \mu \mathrm{g} / \mathrm{ml})$ was 8 -fold lower than that for moxifloxacin $(2 \mu \mathrm{g} / \mathrm{ml})$ and 32 -fold lower than those for azithromycin and tetracycline $(8 \mu \mathrm{g} / \mathrm{ml})$. There was no difference in activity of any antimicrobials against $U$. parvum versus $U$. urealyticum. This collection included 4 isolates of $U$. parvum and 7 isolates of $U$. urealyticum with macrolide resistance (azithromycin MICs of $\geq 32 \mu \mathrm{g} / \mathrm{ml}$ ), tetracycline resistance (MICs, 8 to $>32 \mu \mathrm{g} / \mathrm{ml}$ ), and/or fluoroquinolone resistance (moxifloxacin MICs, 4 to $8 \mu \mathrm{g} / \mathrm{ml}$ ). One isolate of $U$. urealyticum was resistant to both tetracycline and moxifloxacin, and another was resistant to tetracycline and azithromycin. Eravacycline MICs were unaffected by macrolide, tetracycline, or fluoroquinolone resistance.

Eravacycline is a fluorocycline that is structurally similar to tigecycline with modifications to the $D$ ring of its tetracycline core, in which a fluorine atom replaces the dimethylamine moiety and a pyrrolidinoacetamido group replaces the 2-tertiary-butyl glycylamido (12). In 2018, the FDA granted approval for an intravenous formulation of eravacycline for treatment of complicated intra-abdominal infections (CIAI) in adults. Eravacycline and omadacycline, another synthetic tetracycline derivative, both have a broad spectrum of activity according to in vitro and clinical studies, encompassing many types of Gram-positive and Gram-negative pathogens, including those with multidrug resistance mechanisms $(1,12,13)$.

Our previous studies have demonstrated good activity in vitro for omadacycline (8) as well for as another fluorocycline, TP-271 (14) against M. pneumoniae. The TP-271 $\mathrm{MIC}_{90}$ was $0.004 \mu \mathrm{g} / \mathrm{ml}$ (range, 0.0005 to $0.008 \mu \mathrm{g} / \mathrm{ml}$ ) (14), similar to what we observed for eravacycline, for which MICs ranged from 0.004 to $0.008 \mu \mathrm{g} / \mathrm{ml}$ with an $\mathrm{MIC}_{90}$ of $0.008 \mu \mathrm{g} / \mathrm{ml}$. Our prior experience with omadacycline (8) showed that MICs for $M$. pneumoniae ranged from 0.125 to $0.25 \mu \mathrm{g} / \mathrm{ml}$ with an $\mathrm{MIC}_{90}$ of $0.25 \mu \mathrm{g} / \mathrm{ml}$, signifying that its activity was similar to those of tetracycline and doxycycline, for which $\mathrm{MIC}_{90}$ values were $0.5 \mu \mathrm{g} / \mathrm{ml}$. A previous report in which $M$. pneumoniae was tested against tigecycline indicated that its activity was similar to that of tetracycline, with MICs ranging from 0.06 to $0.25 \mu \mathrm{g} / \mathrm{ml}$ and an $\mathrm{MIC}_{90}$ of $0.25 \mu \mathrm{g} / \mathrm{ml}$ (15). Although there have been few direct comparisons of omadacycline versus eravacycline, one study reported lower MICs for eravacycline against Mycobacterium abscessus (16), consistent with our observation for M. pneumoniae. There are no FDA or CLSI breakpoints for mycoplasmas or ureaplasmas for eravacycline. However, FDA breakpoints are $\leq 0.06 \mu \mathrm{g} / \mathrm{ml}$ for Staphylococcus aureus, Enterococcus spp., and Streptococcus anginosus. A breakpoint of $\leq 0.5 \mu \mathrm{g} / \mathrm{ml}$ has been designated for Enterobacteriaceae species and certain anaerobes. Using these breakpoints as a general guide, eravacycline MICs for M. pneumoniae were below these values for designating susceptibility. Previous studies have also shown eravacycline to be highly active against other respiratory pathogens, including Streptococcus pneumoniae, Moraxella catarrhalis, Haemophilus influenzae, and Legionella pneumophila (1), suggesting a potential role in treatment of CABP.

Urogenital Mycoplasma and Ureaplasma species have more diverse antimicrobial resistance patterns than $M$. pneumoniae, for which naturally occurring resistance is limited to macrolides (7). The present study confirmed that all $M$. hominis isolates, including those with resistance to clindamycin, tetracycline, and moxifloxacin, were inhibited by eravacycline at concentrations of $\leq 0.008 \mu \mathrm{g} / \mathrm{ml}$, well below the FDA MIC breakpoint for susceptibility for Gram-positive bacteria. Our previous study (8) found that omadacycline MICs for $M$. hominis ranged from 0.016 to $0.125 \mu \mathrm{g} / \mathrm{ml}$. The $\mathrm{MIC}_{90}$ was $0.063 \mu \mathrm{g} / \mathrm{ml}$, 8-fold higher than that for eravacycline found in the present study $(0.008 \mu \mathrm{g} / \mathrm{ml})$.

Ureaplasma spp. often have higher MICs than M. hominis for tetracyclines and fluoroquinolones, even in the absence of acquired resistance genes. This was evident in the present study, as indicated by $\mathrm{MIC}_{50}$ values, which were 2 -fold higher for tetracycline $(0.5$ versus $0.25 \mu \mathrm{g} / \mathrm{ml})$ and 8 -fold higher for moxifloxacin $(0.5$ versus 
$0.063 \mu \mathrm{g} / \mathrm{ml}$ ). Our earlier data for omadacycline (8) indicated that it was less potent against Ureaplasma spp. than eravacycline, with MICs ranging from 0.25 to $2 \mu \mathrm{g} / \mathrm{ml}$ and an $\mathrm{MIC}_{90}$ of $2 \mu \mathrm{g} / \mathrm{ml}$. Most eravacycline MICs for Ureaplasma spp. were higher than the FDA breakpoint for susceptibility for Gram-positive bacteria but were lower than the $0.5 \mu \mathrm{g} / \mathrm{ml}$ cutoff designated for Enterobacteriaceae and anaerobes.

M. genitalium urogenital infections can be difficult to treat, and the organisms may rapidly develop resistance to macrolides and fluoroquinolones (9). Tetracycline MICs are generally less than $0.5 \mu \mathrm{g} / \mathrm{ml}$ (7), but we encountered an isolate from the urine of a man with congenital hypogammaglobulinemia who had failed multiple antimicrobial treatment courses, including one of doxycycline, for which the tetracycline and azithromycin MICs were $4 \mu \mathrm{g} / \mathrm{ml}$, moxifloxacin MIC was $2 \mu \mathrm{g} / \mathrm{ml}$, and eravacycline MIC was $2 \mu \mathrm{g} / \mathrm{ml}$. Another isolate from this same man had an eravacycline MIC of $0.125 \mu \mathrm{g} / \mathrm{ml}$ with elevated MICs for azithromycin and tetracycline (32 $\mu \mathrm{g} / \mathrm{ml})$ and moxifloxacin $(8 \mu \mathrm{g} / \mathrm{ml})$. Genome sequencing revealed multiple point mutations in an efflux $A B C$ transporter, suggesting that the function of this efflux transporter may be affected and contribute to the resistance. There was also a single-nucleotide polymorphism in the 16S rRNA gene with unknown impact. There was no evidence of tet $M$ in this strain. This potential new mechanism of tetracycline resistance in $M$. genitalium that also affected eravacycline to some extent will be fully described in a separate publication. Eravacycline resistance in some other bacteria is associated with upregulated, nonspecific intrinsic efflux and with target site modifications such as to the $16 \mathrm{~S}$ rRNA or to certain 30 S ribosomal proteins $(17,18)$, so our findings in $M$. genitalium are new, but not completely unexpected.

Overall, these data suggest eravacycline, in addition to its already approved CIAI indication, may be a useful alternative for treating some respiratory and/or urogenital infections caused by human mycoplasmas and ureaplasmas, including infections caused by macrolide, tetracycline, and fluoroquinolone-resistant organisms, thereby justifying further clinical studies. Availability of an oral formulation will greatly enhance such a possibility. We have also demonstrated that overt tetracycline resistance can occur in M. genitalium, presumably as a result of antimicrobial selective pressure, and is perhaps mediated by an efflux mechanism that can also affect eravacycline activity to some extent.

\section{SUPPLEMENTAL MATERIAL}

Supplemental material is available online only.

SUPPLEMENTAL FILE 1, PDF file, 0.5 MB.

\section{ACKNOWLEDGMENTS}

Financial support was provided by Everest Medicines, Ltd.

Study materials were provided by Tetraphase Pharmaceuticals, Inc. We gratefully acknowledge technical support by Melanie Fecanin.

\section{REFERENCES}

1. Sutcliffe JA, O'Brien W, Fyfe C, Grossman TH. 2013. Antibacterial activity of eravacycline (TP-434), a novel fluorocycline, against hospital and community pathogens. Antimicrob Agents Chemother 57:5548-5558. https://doi.org/10.1128/AAC.01288-13.

2. Waites KB, Xiao L, Liu Y, Balish MF, Atkinson TP. 2017. Mycoplasma pneumoniae from the respiratory tract and beyond. Clin Microbiol Rev 30:747-809. https://doi.org/10.1128/CMR.00114-16.

3. Waites KB, Katz B, Schelonka RL. 2005. Mycoplasmas and ureaplasmas as neonatal pathogens. Clin Microbiol Rev 18:757-789. https://doi.org/10 .1128/CMR.18.4.757-789.2005.

4. Taylor-Robinson D, Jensen JS. 2011. Mycoplasma genitalium: from chrysalis to multicolored butterfly. Clin Microbiol Rev 24:498-514. https://doi .org/10.1128/CMR.00006-11.

5. Lis R, Rowhani-Rahbar A, Manhart LE. 2015. Mycoplasma genitalium infection and female reproductive tract disease: a meta-analysis. Clin Infect Dis 61:418-426. https://doi.org/10.1093/cid/civ312.

6. Waites KB, Ratliff A, Crabb DM, Xiao L, Qin X, Selvarangan R, Tang YW,
Zheng X, Dien Bard J, Hong T, Prichard M, Brooks E, Dallas S, Duffy L, Mixon E, Fowler KB, Atkinson TP. 2019. Macrolide-resistant Mycoplasma pneumoniae in the United States as determined from a national surveillance program. J Clin Microbiol 57:e00968-19. https://doi.org/10.1128/ JCM.00968-19.

7. Waites KB, Lysynyansky I, Bebear CM. 2014. Emerging antimicrobial resistance in mycoplasmas of humans and animals, p 289-322. In Browning G, Citti C (ed), Mollicutes molecular biology and pathogenesis. Caister Academic Press, Norfolk, UK.

8. Waites KB, Crabb DM, Liu Y, Duffy LB. 2016. In vitro activities of omadacycline (PTK 0796) and other antimicrobial agents against human mycoplasmas and ureaplasmas. Antimicrob Agents Chemother 60:7502-7504. https://doi.org/10.1128/AAC.01734-16.

9. Bradshaw CS, Jensen JS, Waites KB. 2017. New horizons in Mycoplasma genitalium treatment. J Infect Dis 216:S412-S419. https://doi.org/10 .1093/infdis/jix132.

10. Pereyre S, Gonzalez P, De Barbeyrac B, Darnige A, Renaudin H, Charron 
A, Raherison S, Bébéar C, Bébéar CM. 2002. Mutations in 235 rRNA account for intrinsic resistance to macrolides in Mycoplasma hominis and Mycoplasma fermentans and for acquired resistance to macrolides in $M$. hominis. Antimicrob Agents Chemother 46:3142-3150. https://doi.org/ 10.1128/aac.46.10.3142-3150.2002.

11. Clinical and Laboratory Standards Institute. 2011. Methods for antimicrobial susceptibility testing of human mycoplasmas: approved guideline. CLSI Document M43-A. Clinical and Laboratory Standards Institute, Wayne, PA.

12. Zhanel GG, Cheung D, Adam H, Zelenitsky S, Golden A, Schweizer F, Gorityala B, Lagace-Wiens PR, Walkty A, Gin AS, Hoban DJ, Karlowsky JA. 2016. Review of eravacycline, a novel fluorocycline antibacterial agent. Drugs 76:567-588. https://doi.org/10.1007/s40265-016-0545-8.

13. Zhanel GG, Esquivel J, Zelenitsky S, Lawrence CK, Adam HJ, Golden A, Hink R, Berry L, Schweizer F, Zhanel MA, Bay D, Lagace-Wiens PRS, Walkty AJ, Lynch JP, 3rd, Karlowsky JA. 2020. Omadacycline: a novel oral and intravenous aminomethylcycline antibiotic agent. Drugs 80: 285-313. https://doi.org/10.1007/s40265-020-01257-4.

14. Grossman TH, Fyfe $C$, O'Brien W, Hackel M, Minyard MB, Waites KB, Dubois J, Murphy TM, Slee AM, Weiss WJ, Sutcliffe JA. 2017. Fluorocycline TP-271 is potent against complicated community-acquired bacte- rial pneumonia pathogens. mSphere 2:e00004-17. https://doi.org/10 $.1128 / \mathrm{mSphere} .00004-17$

15. Kenny GE, Cartwright FD. 2001. Susceptibilities of Mycoplasma hominis, M. pneumoniae, and Ureaplasma urealyticum to GAR-936, dalfopristin, dirithromycin, evernimicin, gatifloxacin, linezolid, moxifloxacin, quinupristindalfopristin, and telithromycin compared to their susceptibilities to reference macrolides, tetracyclines, and quinolones. Antimicrob Agents Chemother 45:2604-2608. https://doi.org/10.1128/aac.45.9.2604-2608.2001.

16. Kaushik A, Ammerman NC, Martins O, Parrish NM, Nuermberger EL. 2019. In Vitro activity of new tetracycline analogs omadacycline and eravacycline against drug-resistant clinical isolates of Mycobacterium abscessus. Antimicrob Agents Chemother 63. https://doi.org/10.1128/ AAC.00470-19.

17. Zheng JX, Lin ZW, Sun X, Lin WH, Chen Z, Wu Y, Qi GB, Deng QW, Qu D, Yu ZJ. 2018. Overexpression of OqxAB and MacAB efflux pumps contributes to eravacycline resistance and heteroresistance in clinical isolates of Klebsiella pneumoniae. Emerg Microbes Infect 7:139. https://doi .org/10.1038/s41426-018-0141-y.

18. Grossman TH, Starosta AL, Fyfe C, O'Brien W, Rothstein DM, Mikolajka A Wilson DN, Sutcliffe JA. 2012. Target- and resistance-based mechanistic studies with TP-434, a novel fluorocycline antibiotic. Antimicrob Agents Chemother 56:2559-2564. https://doi.org/10.1128/AAC.06187-11. 